\title{
Wear resistance and microstructures of nanocrystals reinforced laser melt deposited composite coating
}

\author{
J. N. $\mathrm{Li}^{1-3 *}$, Y. B. Zhang ${ }^{2}$, H. Luo ${ }^{2}$, S. L. Gong ${ }^{3}$, Y. S. Huo ${ }^{1}$ \\ ${ }^{1}$ Shandong Co-Innovation Center of Green Building, Jinan 250101, P. R. China \\ ${ }^{2}$ School of Materials Science and Engineering, Shandong Jianzhu University, Jinan 250101, P. R. China \\ ${ }^{3}$ Beijing Aeronautical Manufacturing Technology Research Institute, Beijing 100024, P. R. China
}

Received 9 December 2014, received in revised form 15 January 2015, accepted 22 January 2015

\begin{abstract}
The Stellite SF12-TiC-Mo-Sn laser melt deposited (LMD) composite coating was produced on a TA1 titanium alloy. Such composite coating was researched using scanning electron microscope (SEM) and a high-resolution transmission electron microscope (HRTEM). It was confirmed that $\mathrm{Ti}_{3} \mathrm{Sn}$ nanocrystals appeared at an intersplat region, which was very compatible to the d-space of the $\mathrm{Ti}_{3} \mathrm{Sn}$ at an orientation of (101). The $\mathrm{Ti}_{3} \mathrm{Sn}$ particles were surrounded by the amorphous phases. Under the action of such composite coating, the micro-hardness distribution of the substrate surface is in a range of $1350-1500 \mathrm{HV}_{0.2}$, and the wear volume loss is $1 / 13$ of a TA1 alloy.
\end{abstract}

K e y w or ds: titanium, sliding wear, lasers, composites

\section{Introduction}

The improved machinery performance and safety (aerospace, automotive, etc.) can be realized by development of the protective LMD wear resistance coatings. LMD composite coating is an effective technology to improve the surface performance of titanium alloys $[1,2]$.

In the recent years, the nano-based material systems have gained the interest of the research and industrial community [3-5]. Moreover, amorphous materials have attracted an increasing amount of attention due to their unique physical, mechanical and chemical properties. Lasers have provided the important opportunities for realization of the nanoamorphous manufacturing $[6,7]$. LMD is a promising approach to producing the amorphous-nanocrystalline composites on metals. Through experiments, it has been confirmed that LMD of the Stellite SF12-TiC-Mo-Sn mixed powders can form the amorphous/nanocrystals reinforced composites, which increases the microhardness of the substrate surface. Mo played an important role in improving the wear resistance of the LMD composites [8]. To our know- ledge, it is the first time that the Stellite SF12-TiC-Mo-Sn mixed powders were deposited on a titanium alloy as the hard composites by a LMD technique. In this study, the microstructures and wear resistance of the Stellite SF12-TiC-Mo-Sn LMD composites on a TA1 alloy were discussed in detail.

\section{Experimental}

The LMD technique was conducted on a $5 \mathrm{~kW}$ transverse-flow continuous-wave $\mathrm{CO}_{2}$ laser materials processing system equipped with four-axis computer numerically controlled (CNC) laser materials processing machine under an Ar ambient atmospheric environment, and coaxial powder feeding device (DPSF-3) was employed to melt the surface of the samples at the same time. Materials used as the substrate: TA1 titanium alloy samples $(8 \mathrm{~mm} \times 8 \mathrm{~mm} \times 35 \mathrm{~mm})$ for the wear test or $(10 \mathrm{~mm} \times 10 \mathrm{~mm} \times 9 \mathrm{~mm})$ for the microstructure analysis, chemical composition of TA1 alloy: $0.2 \mathrm{Fe}, 0.08 \mathrm{C}, 0.03 \mathrm{~N}, 0.18 \mathrm{O}, 0.015 \mathrm{H}$ and bal. Ti. The LMD treated surfaces were ground with emery paper to remove the oxide scale, and rinsed with al-

*Corresponding author: e-mail address: jn2369@163.com 


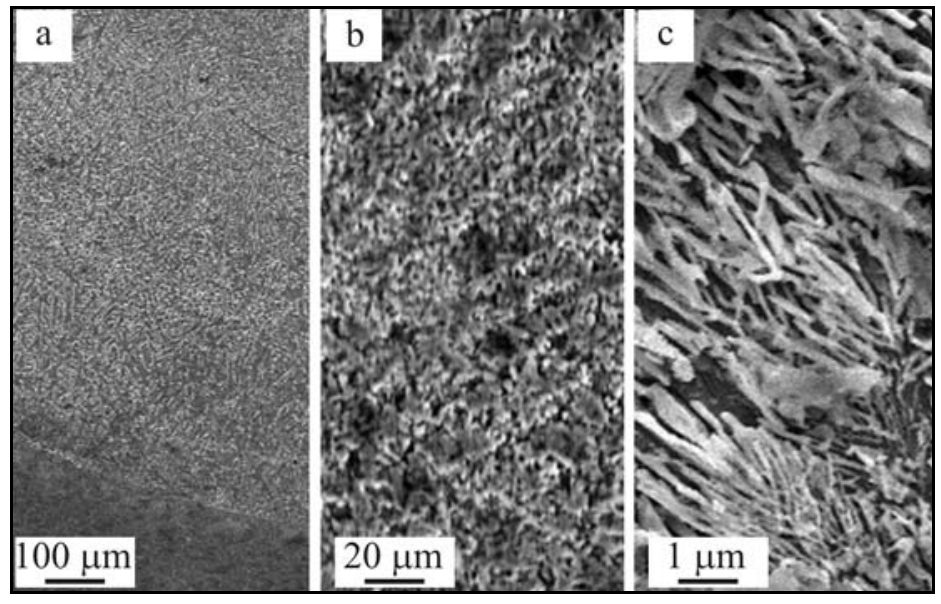

Fig. 1. SEM images of the LMD composite coating in sample 1: (a) bond zone, (b), (c) middle-coating.

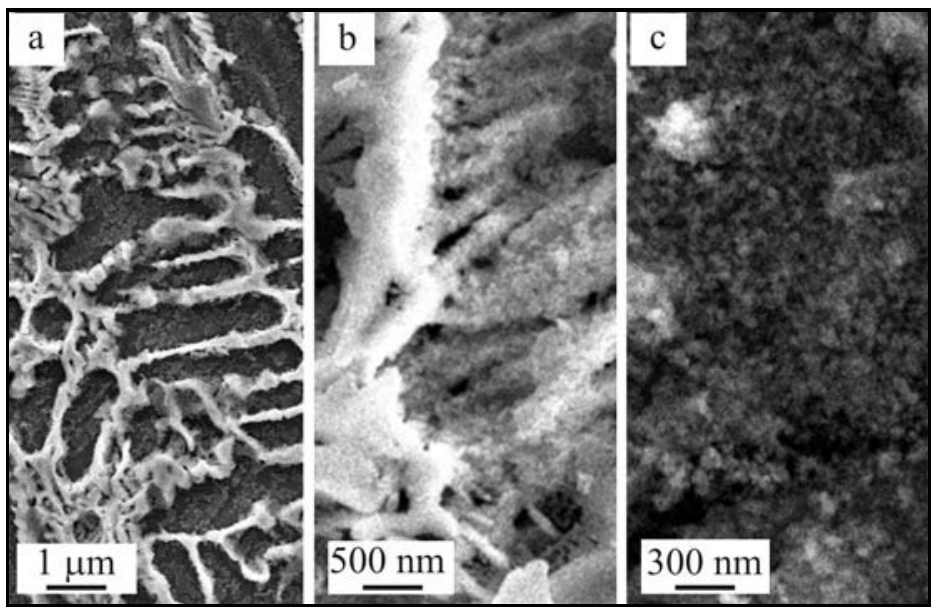

Fig. 2. SEM images of the LMD composite coating in sample 2: (a), (b) nanoscale particles, (c) agglomeration of nanoscale particles.

cohol before the LMD process. The powders mixture of Stellite SF12 ( $\geq 99.5 \%$ purity, 50-100 $\mu \mathrm{m})$, TiC ( $\geq 99.5 \%$ purity, $50-150 \mu \mathrm{m}$ ), Mo $(\geq 99.5 \%$ pur-

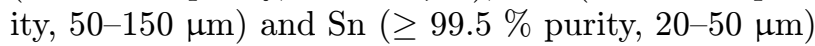
were used for the LMD technique, chemical composition of Stellite SF12: 1.00 C, $19.00 \mathrm{Cr}, 2.80 \mathrm{Si}, 9.00$ $\mathrm{W}, 3.00 \mathrm{Fe}, 13.00 \mathrm{Ni}$, and Bal. Co. Process parameters of LMD: laser power $P=1.15 \mathrm{~kW}$, scanning velocity $V=2-11 \mathrm{~mm} \mathrm{~s}^{-1}$ and the laser beam diameter $D=$ $4.5 \mathrm{~mm}$. An overlap of $35 \%$ between successive tracks was selected. Compositions of the pre-placed powders (wt.\%): 80Stellite SF 12-15TiC-5Mo and 76Stellite SF 12-15TiC-5Mo-4Sn.

The HV-1000 microsclerometer was used to test micro-hardness distribution of the LMD composite coatings. Microstructures of the composite coatings were analyzed using the LEO 1525 scanning electron microscope (SEM) and the Titan 80-300 High-resolution transmission electron microscope (HRTEM). Wear resistance of such LMD composite coatings was tested by the WMM-W1 disc wear tester. The wear volume loss was measured after $60 \mathrm{~min}$. The rotational speed of the wear tester was $415 \mathrm{r} \mathrm{min}^{-1}$. The linear velocity of friction surface was $0.98 \mathrm{~m} \mathrm{~s}^{-1}$.

\section{Results and analysis}

\subsection{Microstructures}

It was noted that the fine and compact composite coating was obtained after the LMD process, and such composite coating was metallurgically bonded to substrate in a sample (see Fig. 1a). As shown in Fig. 1b, fine compact composites were obtained in a sample after LMD process. Lots of the fine stick-shape precipitates are produced in such coating. The fact is that Mo is an active element, and thus during the LMD process, Mo reacted with a portion of the $\mathrm{Si}, \mathrm{Al}$ and $\mathrm{Ti}$ in laser molten pool, leading to the formation of $\mathrm{Mo}_{5}(\mathrm{Si}, \mathrm{Al}, \mathrm{Ti})_{3} \mathrm{C}[9]$ (see Fig. 1c).

It is noted that with the Sn addition, lots of the 


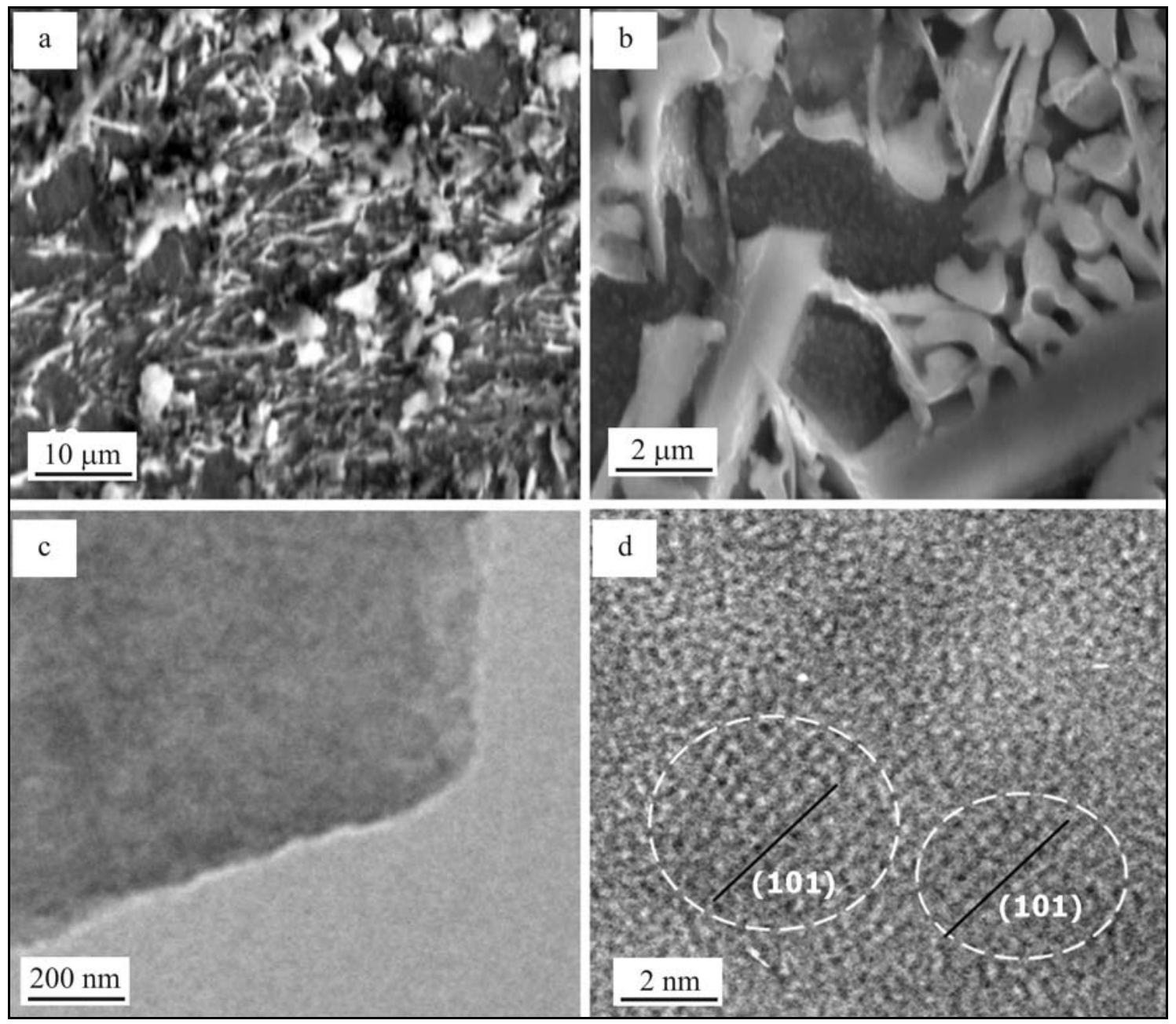

Fig. 3. SEM images of the LMD composite coating: (a) eutectics, and (b) rod-shape precipitates; (c) HRTEM image, and (d) its corresponding HRTEM pattern.

nanoscale particles are produced in such coating, and the skeleton shape austenite was also produced (see Fig. 2a). Owing to a rapid cooling rate of the molten pool, a small amount of elements, such as Si, B and Mo had no time to precipitate from the liquid and solution in $\gamma$-Co to form the supersolution, which caused the solution strengthening. It was also noted that a great number of the nanoscale particles were produced attached to the austenite, which also increased the wear resistance of the coating (see Fig. 2b). Nanoscale particles own a large specific surface, such kind of particles usually gathers together, forming the secondary particles to decrease the interface energy of the system. Thus, the agglomerations of the nanoscale particles were produced in such composites (see Fig. 2c).

Figure 3a shows the SEM image of the eutectics structure in the coating, and also a lot of the fine ceramics were produced attached to them. In fact, the eutectics, such as Co-Ti or Ti-Si binary intermetallic alloy have the uniform and dense microstruc- ture consisting of predominantly the primary dendrites and a minor amount of interdendritic eutectics. Investigation [9] indicated that the Fe-Si-B and Ti-B compounds may show the nano-rods shape in lasertreated composites. The $\mathrm{Fe}_{3}(\mathrm{Si}, \mathrm{B})$ rod-shape precipitates were also produced in such composites (see Fig. 3b).

The test location is shown in Fig. 3c. Figure 3d shows the HRTEM images of three $\mathrm{Ti}_{3} \mathrm{Sn}$ that appeared at an intersplat region. These lattice values are very compatible to the d-space of $\mathrm{Ti}_{3} \mathrm{Sn}$ at an orientation of (101). It was also noted that the $\mathrm{Ti}_{3} \mathrm{Sn}$ particles were surrounded by the amorphous phases. The fact that the glass forming alloy compositions are close to eutectics implies a (relative) low melting point, i.e. the production of the eutectics greatly promoted the formation of the amorphous phases [10].

\subsection{Wear properties}

As shown in Fig. 3, the micro-hardness distribution 


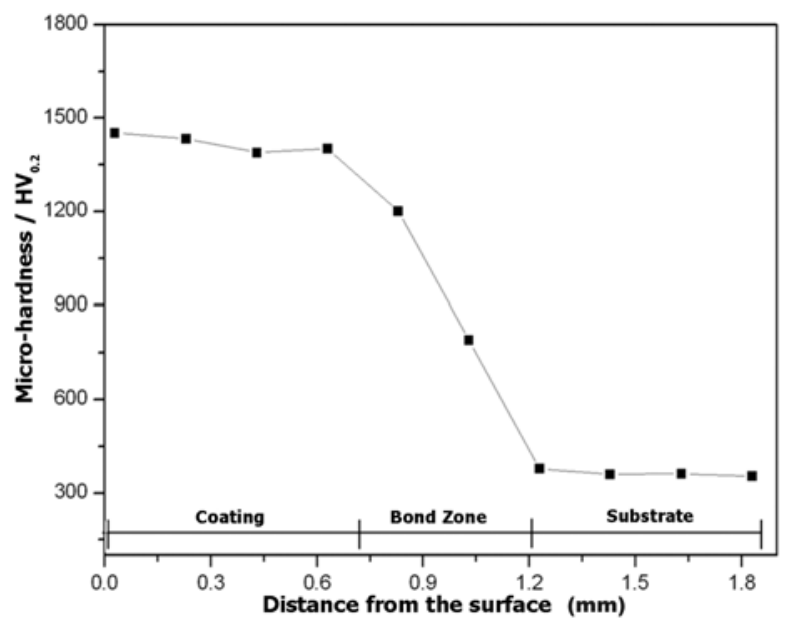

Fig. 4. Micro-hardness distribution of the LMD composite coating.

of such LMD composite coating is in a range of 1350 $1500 \mathrm{HV}_{0.2}$, which is significantly higher than that of a substrate $\left(355 \mathrm{HV}_{0.2}\right)$. The phase constituent, fine grain/nanocrystals strengthening and the amorphous glassy phases all played an important role in increasing the microhardness and wear resistance of such LMD composite coating.

When the load was $55 \mathrm{~N}$, the wear test result indicated that the wear volume loss of the LMD composite coating was about $1 / 13$ of pure TA1. The improvement of wear resistance of LMD coating was mainly ascribed to the actions of many factors, such as the actions of the nanocrystalline-amorphous phases, hard phases, fine grain strengthening of the titanium borides, and the solution strengthening (see Fig. 4). It should be mentioned that owing to a rapid cooling rate of the molten pool, a small amount of the elements, such as $\mathrm{Cr}, \mathrm{W}$ and $\mathrm{Si}$, etc., had no time to precipitate from the liquid and solution in $\gamma-\mathrm{Co} / \mathrm{Ni}$ to form a supersolution, which caused the solution strengthening. Combined with an effect of the micro-hardness enhancement, the strain-hardened tribolayer tends to form on the worn surface, acting as a protective layer to improve wear resistance. Moreover, it should be mentioned that under action of $\mathrm{Sn}$, a lot of the nanoscale particles, such as the $\mathrm{Ti}_{3} \mathrm{Sn}$ nanoscale particles were produced, which also greatly increased the wear resistance of such composite coating; moreover, a lot of the amorphous phases were dispersed in such coating, which decreased the wear volume losses $[11,12]$.

SEM images showed that the worn surface of TA1 was very rough after 60 min wear time. The deep plowing grooves were present on the worn surface of TA1 substrate. Since the micro-hardness of TA1 was significantly lower than that of the counterpart, the hard asperities on the surface of the counterpart penetrated easily into the sliding surface of the substrate, form-

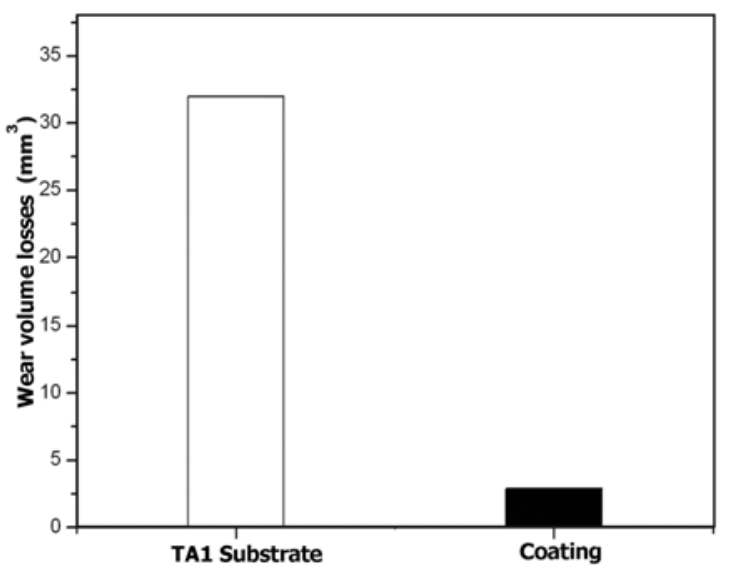

Fig. 5. Wear volume losses of the substrate and the LMD coating.

ing an unsmooth surface (see Fig. 6a). As shown in Fig. 6b, a smooth worn surface of the LMD composite coating was obtained. According to the previous microstructure analysis, due to the action of the laser beam, many hard phases, such as $\mathrm{Ti}_{3} \mathrm{Sn}$ nanocrystalline phases, $\mathrm{Mo}_{5}(\mathrm{Si}, \mathrm{Al}, \mathrm{Ti})_{3} \mathrm{C}$ and different kinds of amorphous phases were produced in this coating, which prevented the stretching of the wear grooves [9]. Moreover, the fine microstructure of composite coating was obtained, which also showed the excellent properties of the plasticity and toughness, favoring the formation of a smooth worn surface.

It should be mentioned that a lot of the brittleness phases existed in some location of such coating, which can be easily peeled off due to the action of the gathering of a lot of the brittleness phases. So the large peeled hole was present on the worn surface (see Fig. 6c). As shown in Fig. 6d, the nano-rods and lots of the other fine precipitates were present in the worn etched surface of the LMD sample. The production of these fine precipitates was beneficial in the production of the smooth surface [13].

\section{Conclusions}

The correct choice of the LMD parameters provided Stellite SF12-TiC-Mo-Sn LMD amorphous/nanocrystals reinforced composite coating on a TA1 titanium alloy with the micro-hardness distribution was in a range of $1350-1500 \mathrm{HV}_{0.2}$, which is significantly higher than that of the substrate $\left(355 \mathrm{HV}_{0.2}\right)$. Many nanocrystalline/amorphous phases were produced, which improved the wear resistance of such composite coating. $\mathrm{Ti}_{3} \mathrm{Sn}$ that appeared at an intersplat region, and the lattice values were very compatible to the d-space of $\mathrm{Ti}_{3} \mathrm{Sn}$ at an orientation of (101). A great number of the nanoscale particles were pro- 


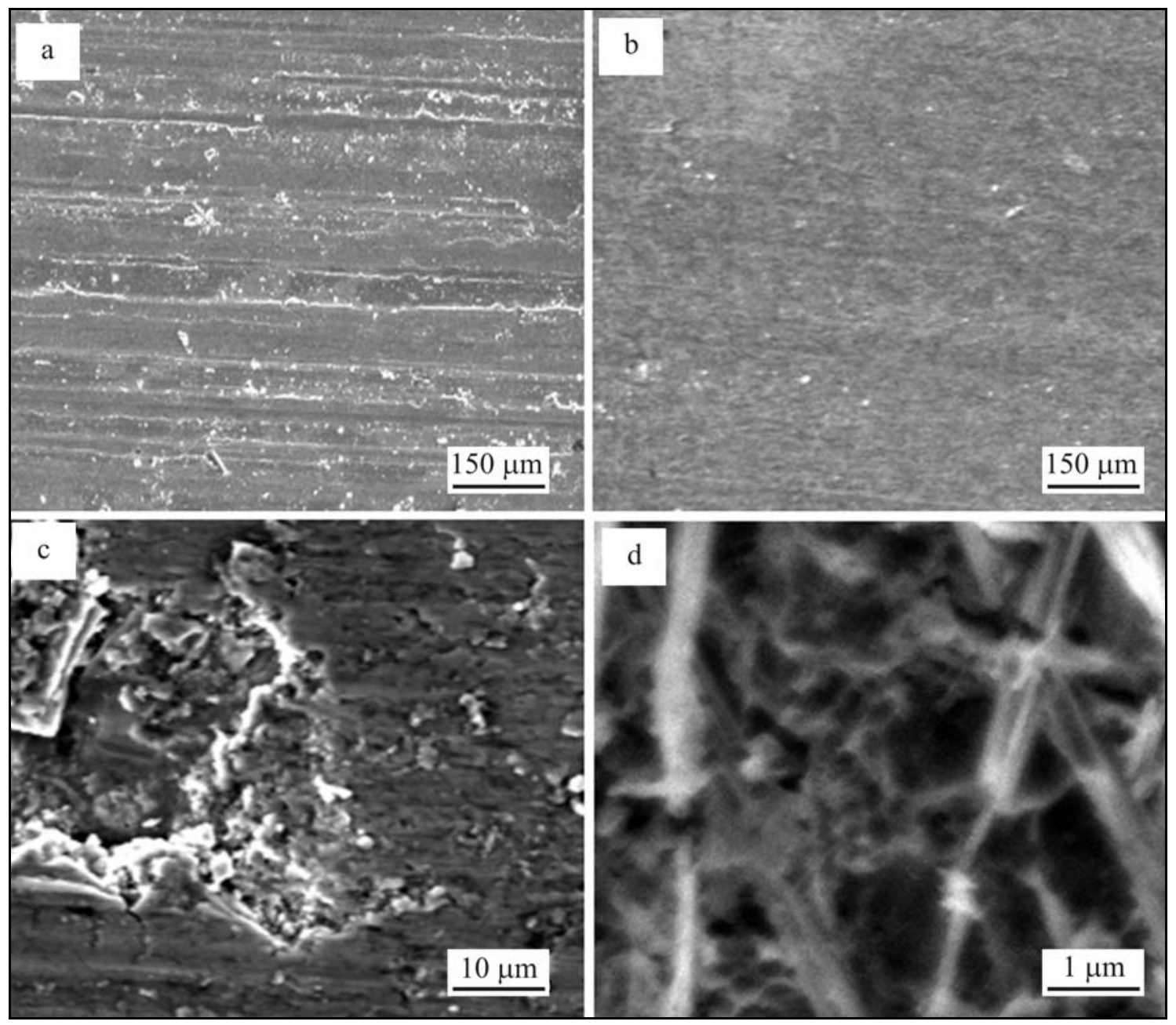

Fig. 6. The worn surface of (a) the TA1 substrate; (b), (c) LMD composite coating, and (d) the etched composite coating in sample 2 .

duced attached to the austenite, which also increased the wear resistance of such coating. The agglomerations of nanoscale particles were produced in such composite coating. When the load was $55 \mathrm{~N}$, the wear test result indicated that the wear volume loss of LMD coating was about $1 / 13$ of the TA1 alloy substrate under the actions of hard phases, fine grain strengthening of the titanium borides, and the nanocrystalline/amorphous phases.

\section{Acknowledgement}

This work was supported by the Natural Science Foundation of China (Grant no. 50472721).

\section{References}

[1] Qu, H. P., Li, P., Zhang, S. Q., Li, A., Wang, H. M.: Mater. Des., 31, 2010, p. 574. doi:10.1016/i.matdes.2009.07.004
[2] Xue, Y., Wang, H. M.: Appl. Surf. Sci., 243, 2005, p. 278. doi:10.1016/j.apsusc.2004.09.073

[3] Gwon, Y. H., Kim, K. W., Cho, K. K.: Mater. Technol.: Adv. Perform. Mater., 27, 2012, p. 27. doi:10.1179/175355511X13240279340525

[4] Li, J. N., Yu, H. J., Chen, C. Z., Li, W.: Kovove Mater., 50, 2012, p. 169.

[5] Li, J. N., Liu, K. G., Gong, S. L., Zhang, Y. B., Liu, P.: Physica E, 66, 2015, p. 317. doi:10.1016/i.physe.2014.10.014

[6] Li, J. N., Gong, S. L., Sun, M., Shan, F. H., Wang, X. C., Jiang, S.: Physica B, 428, 2013, p. 73. doi:10.1016/j.physb.2013.07.018

[7] Li, M. X., He, Y. Z., Yuan, X. M., Zhang, S. H.: Mater. Des., 27, 2006, p. 1114.

[8] Zhang, P. L., Liu, X. P., Lu, Y. L., Yan, H., Yu, Z. S., Li, C. G., Lu, Q. H.: Appl. Surf. Sci., 311, 2014, p. 709. doi:10.1016/j.apsusc.2014.05.141

[9] Li, P.: Int. J. Mater. Prod. Technol., 46, 2013, p. 197. doi:10.1504/IJMPT.2013.056289

[10] Du, B. S., Zou, Z. D., Wang, X. H., Qu, S. Y.: Appl. Surf. Sci., 254, 2008, p. 6489. doi:10.1016/j.apsusc.2008.04.051

[11] Cui, C. Y., Hu, J. D., Liu, Y. H., Gao, K., Guo, Z. X.: 
Appl. Surf. Sci., 254, 2008, p. 6779. doi:10.1016/j.apsusc.2008.04.069

[12] Li, J. N., Gong, S. L.: Physica E, 47, 2013, p. 193. doi:10.1016/j.physe.2012.10.022
[13] Liu, H. X., Xu, Q., Wang, C. Q., Zhang, X. W.: J. Alloys Compd., 621, 2015, p. 357. doi:10.1016/j.jallcom.2014.10.030 